\section{Thalassemia awareness among Iraqi people in 2018}

\author{
Mustafa Majid, Mohammed Tareq \\ Mutar, Hashim Talib Hashim \\ Baghdad University College of \\ Medicine, Baghdad, Iraq
}

\begin{abstract}
Thalassemia is an autosomal recessive disease that is common in Iraq with a prevalence of 35.7 per 100,000 . It is the most common type of hereditary anemia registered in 2015. It is a life-threatening condition with many complications which if not managed could cause death in early age. This study aimed to assess the awareness of Iraqi people about thalassemia transmission and prevention and to find their source of information about the disease, as developing good awareness is the first and the most advantageous road to establish a successful prevention program. This cross-sectional study involved 417 participants who were from medical and non-medical fields. It was conducted as an online survey in addition to participants interview using a self-structured questionnaire which was tested for content and face validity, unidimensionality and test-retest reliability in a pilot study of 40 participants. Each participant who had heard about the disease was given a score (0-5) based on their knowledge: $68.8 \%$ of the people had heard about the disease previously, those had a mean score of 3 out of $5 ; 84 \%$ claimed that thalassemia is a noncommunicable disease which resembles the highest awareness aspect. The lowest one was about the preventability of the disease. Significant correlation was found between the score of awareness and the age. People awareness about thalassemia was relatively good. A control strategy should be directed to elevate the awareness level about thalassemia in the community with the application of the national program for thalassemia control.
\end{abstract}

\section{Introduction}

Thalassemia is the most common type of hereditary anemia registered in Iraq in 16 thalassemic centers in 2015. Both males and females are equally affected by thalassemia and this disorder occurs in approximately 4.4/10,000 live births. Also, it was estimated that the prevalence of beta-thalassemia carrier state is $1.5 \%$ in general population. ${ }^{1}$

Thalassemic patients are susceptible to many complications, like marked hep- atosplenomegaly, which occurs due to excessive red cell destruction $(25.8 \%$ of the patients in Iraq have splenomegaly, and $4.4 \%$ of them have hepatomegaly), extramedullary hematopoiesis, iron overload, osteoporosis $(67.5 \%$ of the patients in Iraq) and osteopenia (9.4\% of the patients in Iraq). ${ }^{1,2}$ And in a study done in 2015, 66.4\% of thalassemia patients were under 15 years with splenomegaly and growth retardation representing the most frequent complications. ${ }^{1}$

Thalassemia represents a great burden. In Iraq, a report from the Federal Board of Supreme Audit in 2016 revealed that the cost of management of each patient is 1428.00-3785.00 US\$/month.

In the Arabian region, high proportions of consanguineous marriages have resulted in a high incidence of genetically based disorders, particularly autosomal recessive ones, and thalassemia is one of them. ${ }^{3,4}$

Thalassemia is a preventable disease, and many countries had succeeded in its prevention through a comprehensive approach starting from spreading knowledge and awareness and developing program to control the disease through premarital investigation and antenatal detection with therapeutic abortion. ${ }^{5-7}$

As awareness is critical in the prevention, it needs assessment in order to identify its level among the general population as well as students from the medical field because some studies showed that even the medical field required more education about the disease prevention methods. ${ }^{4}$

Our aim is to assess the awareness among people about this chronic genetic disease since Thalassemia awareness assessment among population represents the first step in the prevention program, and there is little data available in Iraq about this subject.

\section{Materials and Methods}

This is a cross-sectional study held for one month in august in 2018. This study included 417 participants who were from medical (185) and non-medical fields (232). Sample collection methods included using an online survey in social media sites in addition to participants interview using a self-structured questionnaire.

The questionnaire was tested for validity, unidimensionality, and reliability in a pilot study of 40 participants.

Regarding validity, the questionnaire was developed after reviewing the literature $^{8-10}$ to establish both construct and face validity.

Regarding unidimensionality, it was tested using principal component analysis
Correspondence: Mustafa Majid Hameed, Baghdad University College of Medicine, Baghdad, Iraq. Tel.: +964.7729414006.

E-mail: mustafa.majid.1997@gmail.com

Key words: Thalassemia; awareness; prevention; score; Iraq.

Acknowledgments: the authors would like to acknowledge Dr Rayhan Farooq and Dr Ali Saad Ali for helping in sample collection.

Contributions: MM1, MM2 and HT, conceptualization, resources, data curation, writing, review and editing, visualization; MM1 and MM2, methodology, software, validation, formal analysis, project administration;: MM1, writing, original draft preparation.

Conflict of interests: the authors declare no potential conflict of interests.

vailability of data and materials: All data generated or analyzed during this study are included in this published article.

Received for publication: 2 November 2019. Accepted for publication: 18 December 2019

This work is licensed under a Creative Commons Attribution 4.0 License (by-nc 4.0).

C Copyright: the Author(s), 2020

Licensee PAGEPress, Italy

Thalassemia Reports 2020; 10:8655

doi:10.4081/thal.2020.8655

and only one factor was found to account for the finding; the result can be shown in Table 1. Regarding reliability, test-retest reliability was obtained with interclass correlation coefficient (ICC), the smallest value was 0.69 , and all were statistically significant.

The questionnaire included information about sociodemographic data (age, gender, education level and job, marital status and consanguinity).

The total score was calculated for all those who have heard about the disease so that Do not know answers were considered as incorrect and given a score of (0), whereas the correct answer was given a score of (1). Each of them was given a score (0-5) based on their knowledge in answering the following five questions: i) Is thalassemia a chronic disease?; ii) Is a consanguineous marriage related to thalassemia occurrence?; iii) Is thalassemia a contagious disease?; iv) Is thalassemia a preventable disease?; v) Can thalassemia be transmitted by food?

Descriptive and analytic statistics were done in the term of mean, standard deviation, minimum, maximum, proportions, chi- 
Table 1. Unidimensionality testing.

\begin{tabular}{lccccc} 
Component & Total & $\begin{array}{c}\text { Initial Eigen values } \\
\text { \%of variance }\end{array}$ & $\begin{array}{c}\text { Cumulative\% } \\
\text { Coriance explained }\end{array}$ & $\begin{array}{c}\text { Extraction sums of squared loadings } \\
\text { \%of variance } \\
\text { Cumulative\% }\end{array}$ \\
\hline 1 & 2.032 & 40.646 & 40.646 & 2.032 & 40.646 \\
\hline 3 & 0.930 & 18.594 & 59.240 & \\
4 & 0.817 & 16.340 & 75.580 & \\
\hline 5 & 0.680 & 13.606 & 89.187 & \\
\hline
\end{tabular}

Extraction method: principal component analysis.

square, t-test, and one-way ANOVA with $95 \%$ confidence level which means that a Pvalue less than 0.05 is considered statistically significant.

All participants were informed about the goal of the survey, and informed consent was obtained from them.

The data was analyzed using Social Sciences program (SPSS) version 24.

Table 1 represents unidimensionality testing.

\section{Results}

\section{Results of non-medical sample $(\mathbf{n}=\mathbf{2 3 2})$}

The mean age of the sample is 26.25 years with standard deviation of 8.53 and minimum age of 17 and maximum age of $67,41.17 \%$ were students, $16.7 \%$ had no job, $8.6 \%$ were academic professor, and $8.14 \%$ were students in higher education.

Table 2 represents the educational degree of the participants.

$59.6 \%$ were from Baghdad, 6.1\% were from Al-Nasiriyah, 5.7\% were from Basrah, $4.8 \%$ were from Babil, $4.4 \%$ were from Anbar and same for Dyala, and 3.9\% were from Al-Najaf. the remainder were from other provinces.

$68.8 \%$ of the people have heard about thalassemia previously.

The mean score of the participants who heard about the disease is 3 with a standard deviation of 1.46 .

Table 3 represents the source from where the Participants have heard about the disease (only 202 participants).

A significant weak positive association was noticed between age and the score with $\mathrm{r}=0.22$ and $\mathrm{p}$-value of 0.04 .

No significant association was found between the score and age, gender and if the couples are relatives using T-test with a $\mathrm{P}$ value of $0.85,0.068$ and 0.198 respectively.

\section{Results of medical sample $(n=185)$}

The mean age is 22.3 years with stan-

Table 2. The educational degree of the participants.

\begin{tabular}{llcc} 
& & Frequency & Valid percent \\
Valid & Primary & 3 & 0.7 \\
& Intermediate & 2 & 0.5 \\
& Preparatory & 32 & 7.7 \\
& College & 123 & 29.6 \\
& Higher education & 71 & 17.1 \\
& Medical fields & 185 & 44.5 \\
& Total & 416 & 100.0 \\
Missing & System & 1 & \\
\hline Total & 417 & &
\end{tabular}

Table 3. Source of knowledge about the disease.

\begin{tabular}{lcc} 
Source of knowledge & Valid percent & Frequency \\
Friends and family & 28.8 & 58 \\
Internet & 27.7 & 56 \\
\hline School and college & 22.3 & 45 \\
Hospital visit & 8.9 & 18 \\
\hline Others & 12.3 & 25
\end{tabular}

dard deviation of 3.3. Minimum age was 17 and maximum was 39 years.

$84.9 \%$ were medical students, $5.9 \%$ dentists, $3.2 \%$ pharmacist, $2.7 \%$ physicians, and $3.3 \%$ for other medical fields' careers.

$31.4 \%$ were from Baghdad, $20 \%$ were from Basrah, $15.7 \%$ from Al-Dewaniyah, the remaining of the sample was distributed in different other provinces.

$94 \%$ of the sample have heard about the disease.

The mean score of medical sample was 3.87 with standard deviation of 1.22 .

Table 4 represents other sociodemographic data of the non-medical and medical group.

Table 5 demonstrates the score-based questionnaire answers among medical and non-medical group.

Among non-medical sample, of those who said that thalassemia has relation to consanguineous marriage, $84.1 \%$ of them claimed that consanguineous marriage can increase the risk of thalassemia, $2.3 \%$ claimed that it decreases the risk meanwhile the others did not have information.

Of those who said thalassemia is preventable, $46.7 \%$ claimed that consanguineous marriage prevention is the best way, $32.2 \%$ said that doing test before marriage is the way for prevention, $13.3 \%$ said avoidance of certain foods is the way of prevention, others suggested blood transfusion restriction and avoidance of marriage from the affected ones.

There is statistically significant difference between mean score of medical sample and non-medical sample using $\mathrm{T}$ test of P-value of 0.0001

\section{Discussion}

Thalassemia has a great economic burden in Iraq. It is the most common hereditary hemoglobinopathy in Iraq. ${ }^{1}$ Knowledge and awareness about thalassemia play a significant role in the success of the national program of thalassemia prevention; for this 
reason, this study was conducted. ${ }^{4}$ This study aims to find awareness level among general population and among a particular group who are involved frequently with the subject who are the medical students.

Most of the participants in this study were in their twenties, and this can be confirmed by their mean of age was 26.25, which is a critical age group to be targeted for assessment and evaluation of their awareness about the disease as they are willing to get engaged or having their first child, and they should be aware about this common disease in the community and identify the best method for its prevention.

In this study (regarding non-medical sample), $68 \%$ of the participants identify the disease as a consanguineous marriage related disease, and $84 \%$ of them believed it increases the risk. Studies had shown that avoiding consanguineous marriage is a well-established and effective preventive measure which should be done by educating young couples who have a marriage desire to prevent many recessive diseases including but not limited to thalassemia. ${ }^{8-12}$

When both parents are carriers of a particular gene for any disorder, each child of those parents has a $25 \%$ risk of that recessive disorder. The chance that both parents will be carriers of the gene of the same disorder is influenced by the extent to which the problem is endemic in a community. ${ }^{13}$

The study (regarding non-medical field) shows that participants believed that the best method of prevention is to have a premarital testing. The premarital testing is an essential part in the prevention programs, and it is applied in several countries worldwide such as Cyprus, ${ }^{5}$ Lebanon, ${ }^{6}$ Saudi Arabia, Iran, and United Arab Emirates. ${ }^{7}$

In Iraq, the prevention program is now applied, and every couple is obliged to do premarital investigations including blood tests, but the couples are free to make their decision to proceed with their marriage or not. The WHO recommends that these tests are to be done on voluntary basis ${ }^{14}$ but the high economic burden of the blood diseases in Iraq was the rationale for making them mandatory, the situation is the same in many countries in the Mediterranean region. Some countries applied screening test among secondary school students in order to identify those at risk before they have a desire or arrangement for marriage.
A study done in Duhok, in north Iraq, showed that about 54,132 couples who were willing to get engaged were tested and 130 of them were found to be at risk; $98.1 \%$ of them decided to proceed with their marriage after they knew that. ${ }^{15}$ So it is necessary to educate couples and to spread awareness about the disease.

As the contagious diseases have many impacts including stigma, it is necessary to identify Thalasssemia as a non-contagious disease to protect patients from being stigmatized. $84.5 \%$ of the non-medical people field described the disease as a non-contiguous disease, and it is known that all genetic diseases are not infectious in nature. Thalassemia is transmitted in an autosomal recessive fashion in majority of cases; in very rare cases it is associated with a dominant mutation. ${ }^{16,17}$

Essential for the awareness is to assess the source of information about the disease and its prevention. The most frequent source of information was from families or friends, followed by social media sites; this might give a good indicator of raising community awareness about thalassemia if more attention is given for social media.

Table 4. Sociodemographic data in both groups.

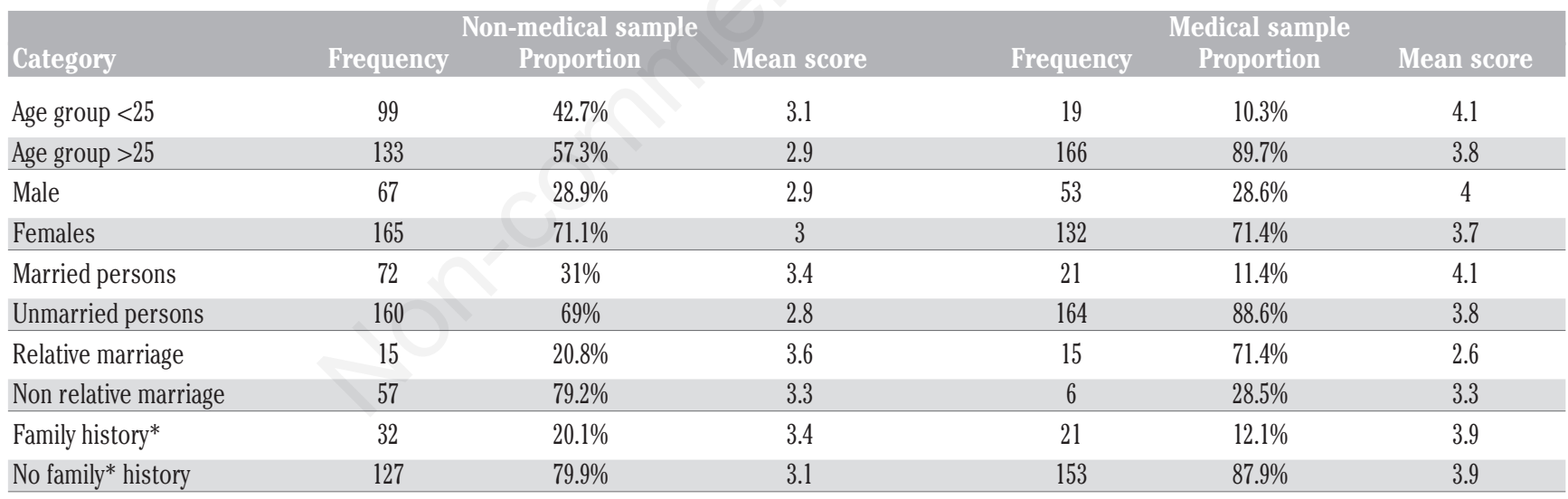

*Of those who have heard about the disease.

Table 5. Items' answers of awareness among medical and non-medical sample.

\begin{tabular}{|c|c|c|c|c|c|c|}
\hline \multirow[b]{2}{*}{ Question } & \multicolumn{3}{|c|}{ Non-medical sample } & \multicolumn{3}{|c|}{ Medical sample } \\
\hline & Yes $(\%)$ & No $(\%)$ & I don't know (\%) & Yes $(\%)$ & No $(\%)$ & I don't know (\%) \\
\hline Is thalassemia a chronic disease? & $136(58.7)$ & $\begin{array}{c}22 \\
(9.6)\end{array}$ & $\begin{array}{c}74 \\
(31.7)\end{array}$ & $\begin{array}{c}159 \\
(85.9)\end{array}$ & $\begin{array}{c}7 \\
(4.1)\end{array}$ & $\begin{array}{c}19 \\
(10)\end{array}$ \\
\hline Is consanguineous marriage related thalassemia occurrence? & $\begin{array}{c}160 \\
(68.8)\end{array}$ & $\begin{array}{c}21 \\
(8.9)\end{array}$ & $51(22.3)$ & $\begin{array}{c}163 \\
(88.3)\end{array}$ & $\begin{array}{c}5 \\
(2.3)\end{array}$ & $\begin{array}{c}17 \\
(9.4)\end{array}$ \\
\hline Is thalassemia a contagious disease? & $8(3.6)$ & $195(84)$ & $29(12.4)$ & $\begin{array}{c}3 \\
(1.8)\end{array}$ & $\begin{array}{c}169 \\
(91.2)\end{array}$ & $\begin{array}{c}13 \\
(7.1)\end{array}$ \\
\hline Is thalassemia a preventable disease? & $100(43.1)$ & $38(16.2)$ & $94(40.7)$ & $\begin{array}{c}104 \\
(56.2)\end{array}$ & $\begin{array}{c}29 \\
(15)\end{array}$ & $\begin{array}{c}52 \\
(28.4)\end{array}$ \\
\hline
\end{tabular}


This is different from a study done by Ahmed et al..$^{18}$ and Abd Al Azeem et al. ${ }^{19}$ in which television was the most frequent source of their knowledge, followed by friends and relatives.

Medical students' awareness was the the lowest in prevention aspects, and this goes with the findings of Zulkeflle et al. ${ }^{4}$ for this reason, the college students are targeted to assess their knowledge about prevention, particularly about premarital investigation test. ${ }^{20}$

Important to be mentioned in this study is that it is a complementary study to a previous study conducted among thalassemia patients' parents to assess their awareness. ${ }^{21}$

As a limitation, this study was conducted as an online survey and only those with internet access had the chance of participation in the study so an important part to be considered in next studies is to address those living in villages and those without internet access to involve them in the study in order to have a full clear image about the awareness of the disease in a more precise and clear way. And the authors encourage future researchers to use this questionnaire to assess thalassemia awareness in these areas as it was proved to be valid and reliable.

\section{Conclusions}

People awareness about thalassemia was relatively good, the highest awareness was for the contiguity of the disease and the lowest awareness was for the preventability. More awareness programs will be beneficial for prevention of the disease.

\section{References}

1. Kadhim KA, Baldawi KA, Lami FH. Prevalence, incidence, trend, and com- plications of thalassemia in Iraq. Hemoglobin 2017;41:164-8.

2. Al Jadir SM, Jalal MZ, Al Ghree MF, et al. Osteoporosis in Iraqi patients with thalassemia. Arthritis Res Ther 2012; $14: 4$.

3. Ahmad WIU, Atkin K, Chamba R. Causing havoc to their children: parental and professional perspectives on consanguinity and childhood disability. In: Ahmad WIU, editor. Ethnicity.Disability and Chronic Illness, Buckingham: Open University Press; 2000.

4. Zulkeflle MZ, Venkateswaran SP, Barua A. Knowledge, awareness and participation of medical and non-medical students in the Malaysia National Thalassemia Prevention Programme. Int J Hum Genet 2015;15:61-72.

5. Kalokairinou EM. The experience of $\beta$ thalassaemia and its prevention in Cyprus. Med Law 2007;26:291-307.

6. Inati $\mathrm{A}$, Zeineh $\mathrm{N}$, Isma'eel $\mathrm{H}$, et al. $\beta$-Thalassemia: the Lebanese experience. Clin Lab Haematol 2006;28:21727.

7. Rudra S, Chakrabarty P, Hossain MA, et al. Awareness among parents of $\beta$ thalassemia major patients regarding prenatal diagnosis and premarital screening in Day Care Centre of Transfusion Medicine Department. Mymensingh Med J 2016;25:12-7.

8. Jenn NC. Designing a questionnaire. Malaysian Fam Phys 2006;1:32-5.

9. Boynton PM, Greenhalgh T. Selecting, designing, and developing your questionnaire. BMJ 2004;328;1312.

10. Leung WC. How to conduct a survey. Student BMJ 2001;9:143-5.

11. Samavat A, Modell B. Iranian national thalassaemia screening programme. BMJ 2004;329:1134-7.

12. Antonio C, Kan YW. The Prevention of Thalassemia. Cold Spring Harbor Perspect Med 2013;3:1.
13. Darr A, Small N, Ahmad WI, et al. Addressing key issues in the consanguinity-related risk of autosomal recessive disorders in consanguineous communities: lessons from a qualitative study of British Pakistanis. J Comm Gen 2016;7:65-79.

14. WHO Proposed international guidelines on ethical issues in medical genetics and genetic services: report of WHO meeting on Ethical Issues in Medical Genetics; 15-16 December 1997. Geneva: World Health Organization; 1998. Available form: https://apps.who. int/iris/handle/10665/63910

15. Al-Allawi NA, Jalal SD, Ahmed NH, et al. The first five years of a preventive programme for haemoglobinopathies in Northeastern Iraq. J Med Screening 2013;20: 171-6.

16. Galanello R, Origa R. Beta-thalassemia orphanet. J Rare Dis 2010;5:1172-5.

17. Smith RA, Hughes D. Infectious disease stigmas: maladaptive in modern society. Commun Stud 2014;65:132-8.

18. Ahmed D, Zafar H, Tauseef K, et al. Identification of common ways for thalassemia awareness in medical and nonmedical professionals. UKJPB 2017;4: $1-5$.

19. Abd Al-Azeem ST, Elsayed ET, ElSherbiny NA, Ahmed LA. Promotion of knowledge and attitude towards premarital care: an interventional study among medical student in Fayoum University. J Pub Health Epidemiol 2011;3:121-8.

20. Lena-Russo D, Badens C, Aubinaud M, et al. Outcome of a school screening programme for carriers of haemoglobin disease. J Med Screening 2002;9:67-9.

21. Mutar M, Majid M, Jaleel A, et al. Awareness among parents of beta thalassemia major and intermedia patients in three centers in Baghdad and AlNasiriyah, Iraq in 2017. Int J Med Students 2019;7:6-10. 